\title{
A Comparative Study of Antrochoanal Polyp in Children and Adults
}

\author{
Jin Yoon, Joon Sang Yu, and Jae Hoon Lee \\ Department of Otolaryngology-Head and Neck Surgery, Institute of Wonkwang Medical Science, College of Medicine, \\ Wonkwang University, Iksan, Korea
}

\section{소아와 성인에서의 상악동후비공비용에 관한 비교 연구}

윤 진 · 유준상 - 이재훈

원광대학교 의과대학 이비인후과학교실

Received November 11, 2017 Revised December 9, 2017 Accepted December 11, 2017 Address for correspondence Jae Hoon Lee, MD Department of OtolaryngologyHead and Neck Surgery, Institute of Wonkwang Medical Science, College of Medicine, Wonkwang University, 895 Muwang-ro, Iksan 54538, Korea Tel +82-63-859-1441 Fax $+82-63-841-6556$ E-mail leejaehoon64@gmail.com
Background and Objectives Antrochoanal polyp (ACP) is defned as a polyp that originates in the maxillary sinus. The polyps are usually seen in children and adolescents. The aim of this study was to compare the characteristics between the child and adults groups who have ACP. Subjects and Method A total of 55 patients who underwent endoscopic sinus surgery for ACP was enrolled in this study. The population of this study was divided into child ( $\leq 17$ years old) and adult ( $\geq 18$ years old) groups. The clinical data and $\mathrm{CT}$ fndings including stages, maxillary sinus retention cyst (MSRC) of non-ACP lesion side, and accompanying sinusitis using Lund-Mackay score were retrospectively investigated.

Results On CT stage of ACPs and MSRC, there were no signifcant differences between the two groups $(p>0.05)$. The accompanying sinusitis was more common in child group $(p<0.05)$. Endoscopic sinus surgery (ESS) combined canine fossa approach as well as ESS alone were the effective methods in treating ACPs in both groups.

Conclusion The accompanying sinusitis could be common in children with ACPs, which should be treated with ACPs simultaneously.

Korean J Otorhinolaryngol-Head Neck Surg 2018;61(8):408-11

Key Words Adult $\cdot$ Antrochoanal polyp $\cdot$ Child $\cdot$ Sinusitis.

\section{서 론}

상악동후비공비용(antrochoanal polyp, $\mathrm{ACP}$ )은 상악동 점막에서 발생하는 단일 용종으로 자연공이나 부공을 통하 여 자라 나와 중비도를 확장시키고 후비공이나 비인강으로 돌출된다. $\mathrm{ACP}$ 는 전체 비용의 3 6\%를 차지하며, 일반적인 비용이 소아에서 드물고, 성인에서 잘 생기는 반면 $\mathrm{ACP}$ 는 소 아나 젊은 연령층에서 호발하는 것으로 되어 있다.

$\mathrm{ACP}$ 의 발생 원인은 잘 밝혀져 있지 않지만, Berg 등ํㅡㄴ 상

This is an Open Access article distributed under the terms of the Creative Commons Attribution Non-Commercial License (https://creativecommons.org/licenses/by-nc/4.0) which permits unrestricted non-commercial use, distribution, and reproduction in any medium, provided the original work is properly cited.
악동 저류낭종(maxillary sinus retention cyst)이 $\mathrm{ACP}$ 의 기원 이 될 것이라고 하였다. Frosini 등른 상악동 낭종이 있는 상 태에서 상악동 내 염증으로 인해 상악동 자연공이 좁아지게 되면 상악동 내로 들어온 공기가 빠져나가지 못하여 상악동 내에 양압이 생성되고 상악동 낭종이 부공을 통해 탈출되어 $\mathrm{ACP}$ 가 발생한다고 하였다.

$\mathrm{ACP}$ 연구는 대부분 소아를 대상으로 하였고, 소아와 성인 에 따른 $\mathrm{ACP}$ 비교 연구는 매우 미미한 상태이다. 이에 저자 들은 소아와 성인에 따른 $\mathrm{ACP}$ 의 임상적 양상 및 부비동 단 층촬영을 통한 방사선학적 연구를 통해 $\mathrm{ACP}$ 병기, 상악동 낭종 발생 유무, 동반된 부비동염에 차이가 있는지 알아보고 자 하였다. 


\section{대상 및 방법}

\section{대 상}

2004년부터 2012년까지 원광대학교병원에 내원하여 비내 시경검사와 부비동 전산화단층촬영을 통해 $\mathrm{ACP}$ 로 진단되어 1 인의 동일 전문의에게 수술을 받은 환자 중 2 년 이상 추적 관찰이 가능했던 환자를 대상으로 하였다. 총 55명의 환자 중 18 세를 기준으로 17 세 이하군(소아군)과 18 세 이상군(성인군) 으로 구분하였다. 본 연구는 원광대학교병원 임상시험심사위 원회 심의면제(WKUH 1821)를 받은 후 진행되었다.

\section{부비동 단층촬영을 통한 분석}

55 명의 연구 대상군을 부비동 단층촬영(Somatom Definition Flash 256-slice CT scanners; Simens Healthcare, Forchheim, Germany)을 이용하여 $1 \mathrm{~mm}$ 두께로 축상면을 측정 하였으며, 관상면과 시상면은 Wizard workstation(Siemens Healthcare)을 통해 $2 \mathrm{~mm}$ 두께로 재구성되었다.

부비동 전산화단층촬영의 영상을 이용하여 다음의 3가지 항목에 대하여 분석하였다.

1) 2002년 Chung 등희의 보고에 따라 각각의 환자 병기를 세 가지로 분류하였다. 간단히 기술하면, 1 기는 $\mathrm{ACP}$ 가 비인 강에 이르지 못한 경우, 2 기는 $\mathrm{ACP}$ 가 비인강에서 확인이 가 능하고 상악동과 비강 내 용종의 연결 부위가 용종에 의해 완 전히 막혀 있는 경우, 3 기는 $\mathrm{ACP}$ 가 비인강에서 확인이 가능하 고 상악동과 비강 내 용종의 연결 부위가 용종에 의해 완전 히 막히지 않은 경우이다.

2) $\mathrm{ACP}$ 병변측이 아닌 반대측의 상악동에서 저류 낭종 발 생 유무를 관찰하였다.

3) $\mathrm{ACP}$ 와 부비동염과의 관계로서 $\mathrm{ACP}$ 병변측 및 반대측의 Lund-Mackay score(L-M 점수 $)^{4}$ 를 확인하였다.

\section{통 계}

통계학적 분석은 SPSS version 12.0 program(SPSS Inc., Chicago, IL, USA)을 이용하여 1군과 2군 간의 병기 비교에 는 chi-square test, 반대측 저류낭종 발생 비교에는 Fisher's exact test, L-M 점수 비교에는 Mann-Whitney test를 사용 하였다. 유의성은 $p$ 값이 0.05 미만인 경우에 통계적으로 유 의하다고 판정하였다.

\section{결 과}

임상적 분석(Table 1 and 2)

소아군은 21 명이며 평균연령은 12.1 세로 남녀 비는 16:5였고,
Table 1. Clinical data of both child and adult groups

\begin{tabular}{lcc}
\hline \multicolumn{1}{c}{ Characteristics } & Child $(\mathrm{n}=21)$ & Adult $(\mathrm{n}=34)$ \\
\hline Age (years) & $12.1 \pm 2.5$ & $33.6 \pm 3.7$ \\
Sex $(\mathrm{M}: \mathrm{F})$ & $16: 5$ & $18: 16$ \\
Location (R:L) & $14: 7$ & $12: 22$ \\
ESS Hx, \% & $3(14.2)$ & $8(23.5)$ \\
Origin site (MS), \% & & $8(23.5)$ \\
$\quad$ Posterior & $5(23.8)$ & $22(64.7)$ \\
Posterolateral & $15(71.4)$ & $4(11.8)$ \\
$\quad$ Undefined & $1(4.8)$ & \\
\hline
\end{tabular}

M: male, F: female, R: right, L: left, ESS: endoscopic sinus surgery, $\mathrm{Hx}$ : history, MS: maxillary sinus

Table 2. Surgery data of both child and adult groups

\begin{tabular}{lcc}
\hline \multicolumn{1}{c}{ Characteristics } & Child & Adult \\
\hline OP $(\%)$ & $85.7(18 / 21)$ & $76.4(26 / 34)$ \\
First & $14.2(3 / 21)$ & $23.5(8 / 34)$ \\
Revision & & \\
Approach (\%) & $23.8(5 / 21)$ & $23.5(8 / 34)$ \\
MMA & $76.1(16 / 21)$ & $76.4(26 / 34)$ \\
MMA+CP & & \\
Recurrence (\%) & $20.0(1 / 5)$ & $0.0(0 / 8)$ \\
MMA & $6.25(1 / 16)$ & $15.3(4 / 26)$ \\
MMA+CP & & \\
\hline
\end{tabular}

OP: operation, MMA: middle meatal antrostomy, CP: canine puncture

병변측은 좌측이 7 명, 우측이 14 명이었다. 성인군은 34 명으로 평균연령은 33.6세로 남녀 비는 18:16이었고, 병변측은 좌측이 22 명, 우측이 12 명이었다. 총 55 명의 환자 중 11 명이 $\mathrm{ACP}$ 에 대 한 과거 수술력이 있었는데 소아군은 3명, 성인군은 8명이었다. $\mathrm{ACP}$ 는 상악동의 후벽 혹은 후외벽에서 대부분 기시하였으며 소아군에서는 후벽에서 5명(23.8\%), 후외벽에서 15명(71.4\%), 기시 부위를 확인하기 어려웠던 경우가 1 명 $(4.8 \%)$ 이었다. 성 인군에서는 후벽에서 8명(23.5\%), 후외벽에서 22명(64.7\%), 기시 부위를 확인하기 어려웠던 경우가 4 명(11.8\%)이었다.

$\mathrm{ACP}$ 에 대한 수술 접근은 부비동 내시경 수술을 통한 중비 도 상악동 개방술(middle meatal antrostomy, MMA)을 통 해 $\mathrm{ACP}$ 를 제거하였거나, $\mathrm{MMA}$ 를 통해 $\mathrm{ACP}$ 를 제거하기가 어 려웠던 경우에 견치와(canine puncture, $\mathrm{CP}$ ) 접근법을 추가 적으로 시행하였다. 소아군에서 $\mathrm{MMA}$ 접근법은 21 명 중 5명 (23.8\%)이었고, $\mathrm{MMA}+\mathrm{CP}$ 접근법은 21명 중 16명(76.1\%)이었 다. 성인군에서 $\mathrm{MMA}$ 접근법은 34명 중 8명(23.5\%)이었고, $\mathrm{MMA}+\mathrm{CP}$ 접근법은 34명 중 26명(76.4\%)이었다.

수술 후 재발은 소아군에서 MMA 접근법인 경우 5명 중 1 명(20.0\%)이었고, $\mathrm{MMA}+\mathrm{CP}$ 접근법은 16명 중 1명(6.25\%) 이었다. 성인군에서 $\mathrm{MMA}$ 접근법인 경우 8 명 중 재발은 없었 으며, $\mathrm{MMA}+\mathrm{CP}$ 접근법은 26명 중 4명(15.3\%)이었다. 재발된 


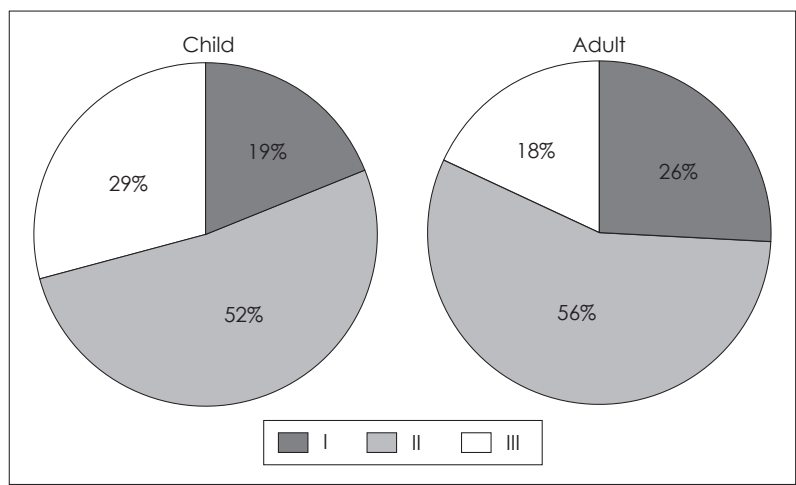

Fig. 1. Each of CT stage of both child and adult groups. On CT stage of antrochoanal polyps, there are not significantly different between two groups $(p>0.05)$.

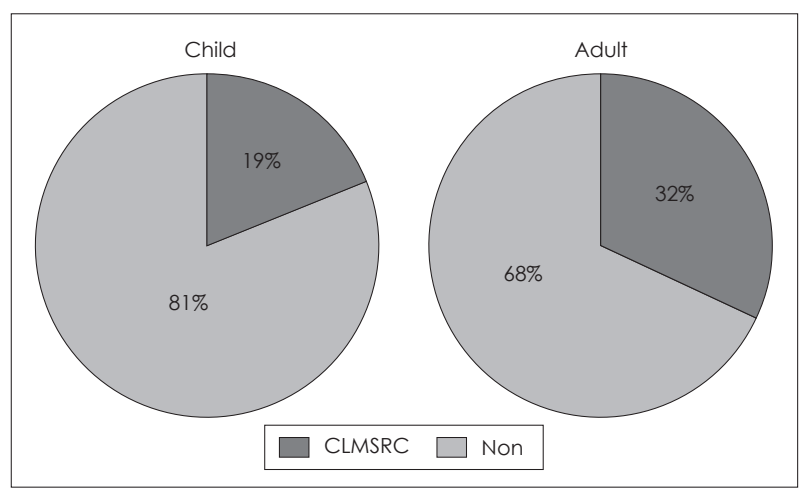

Fig. 2. Contralateral maxillary sinus retention cyst of both child and adult groups. On maxillary sinus retention cyst of non-antrochoanal polyps lesion side, there are not significantly different between two groups $(p>0.05)$. CLMSRC: contralateral maxillary sinus retention cyst.

6명은 $\mathrm{MMA}+\mathrm{CP}$ 접근법을 통해 재수술을 시행하였으며 그 후 재발 소견은 없었다.

\section{부비동 단층촬영을 통한 분석}

\section{연구군의 병기(Fig. 1)}

소아군에서 1기는 21명 중 4명(19\%), 2기는 11명(52\%), 3기는 6명(29\%)이었으며, 성인군에서는 1기는 34명 중 9명(26\%), 2 기는 19 명 $(56 \%), 3$ 기는 6 명(18\%)이었다. 연구군 간에 병기별 유의한 차이를 보이지 않았다 $(p>0.05)$.

\section{저류낭종의 발생(Fig. 2)}

소아군에서 반대측 저류낭종은 21명 중 4명(19\%)이었으며, 1 개인 경우가 2 명, 3 개 이상의 다발성인 경우가 2 명이었고, 성 인군에서 34명 중 11명(32\%)이었으며, 1개인 경우가 9명, 2개 인 경우가 2 명, 3 개 이상의 다발성인 경우는 없었다. 연구군 간에 유의한 차이를 보이지 않았다 $(p>0.05)$.

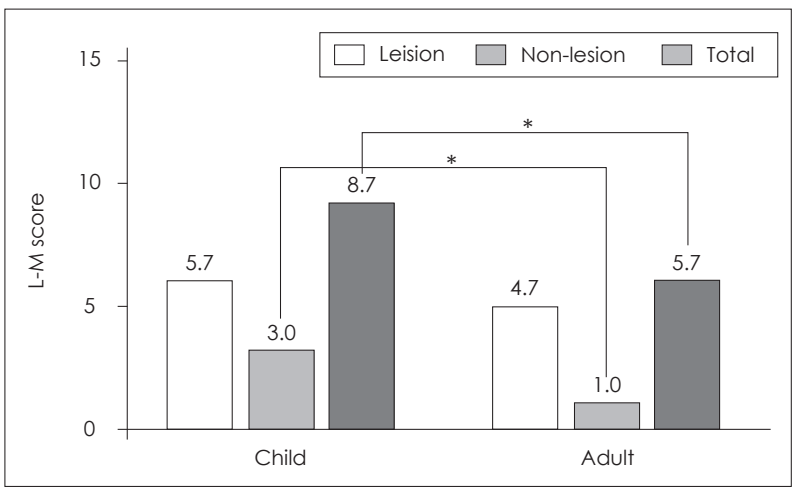

Fig. 3. L-M score of both child and adult groups. The accompanying sinusitis was more common in child group $(p<0.05)$. The lesion site means an antrochoanal polyp side. ${ }^{*} p<0.05$. L-M: LundMackay.

\section{$\mathrm{L}-\mathrm{M}$ 점수(Fig. 3)}

소아군에서 병변측이 5.7점, 반대측이 3.0점, 성인군에서 병 변측이 4.7점, 반대측이 1.0점이었다. 총 점수는 소아군에서 8.7점, 성인군에서 5.7점이었다. 연구군 간에 병변측 L-M 점 수는 유의한 차이를 보이지 않았다. 그러나 반대측과 양측을 합한 총 점수는 연구군 간에 각각 유의한 차이를 보였다 $(p=0.028, p=0.044)$.

\section{고 찰}

본 연구는 부비동 전산화단층촬영의 영상을 이용하여 3가 지 항목에 대하여 분석하였다. 첫째, $\mathrm{ACP}$ 병기에 대한 분석 이었다. Chung 등 ${ }^{3}$ 의 보고에 따른 $\mathrm{ACP}$ 병기는 부비동 단층 촬영 영상에서 보이는 용종의 모양에 따라 $\mathrm{ACP}$ 정도를 추 정하여 본 것으로 $\mathrm{ACP}$ 가 상악동에서 점점 자라 나와 부공 을 통하여 비강으로 나와 비인강에 도달한 후, 그 뒤에 점점 퇴화하면서 stalk가 수축되어 부공이 보이게 되고, 비인강 내 용종은 그대로 남아 있게 되는 것으로 추정되었다.

Lee 등 ${ }^{5)}$ 이 최근 보고된 $\mathrm{ACP}$ 연구에서는 소아군에서 1기 는 27명 중 1명(3.7\%), 2기는 22명(81.5\%), 3기는 4명(14.8\%) 이었으며, 성인군에서는 1 기는 29명 중 13명(44.8\%), 2기는 12 명(41.4\%), 3기는 4명(13.8\%)이었다. 소아군에서는 2기가, 성 인군에서는 1 기가 가장 많았으며, 소아군에서 1 기에 비해 2 기와 3기에서 유의하게 많았는데 그에 대한 이유로 소아에서 $\mathrm{ACP}$ 의 늦은 진단으로 인해 보다 진행된 경우가 많았던 것으 로 추정되었다. 15 명의 $\mathrm{ACP}$ 환자를 대상으로 한 연구에서 1 기는 3명(20\%), 2기는 7명(47\%), 3기는 5명(33\%)이었으며, 1 기는 전부 15 세 이하로 평균 9.3세, 2 기는 평균 21 세, 3 기는 전부 15 세 이상으로 평균 27.8 세였다. ${ }^{3)} \mathrm{Lee}$ 등 ${ }^{5}$ 의 연구에서는 성인군에서 1 기가 가장 많았으나 본 연구에서는 2 기가 가장 
많아 서로 다른 결과를 보였다.

둘째, 저류낭종의 발생률에 대한 분석이었다. 상악동 저류 낭종의 발생률은 전체 인구의 8 10\%로 알려져 있다. ${ }^{6)} \mathrm{Berg}$ 등 $^{1)}$ 은 상악동 저류낭종이 $\mathrm{ACP}$ 의 기원이 될 것이라고 주장하 였다. Balikci 등 ${ }^{7)}$ 은 34명의 ACP 환자를 대상으로 한 연구 에서 평균 24.94세였으며, 반대측 저류낭종이 $32.3 \%$ 에서 관 찰되었는데 이런 결과는 평균 발생률인 8 10\%보다 높았다. 본 연구에서는 소아군에서 반대측 저류낭종은 21 명 중 4 명 $(19.0 \%)$ 이었으며, 1 개인 경우가 2 명, 3 개 이상의 다발성인 경우 가 2 명이었고, 성인군에서 34 명 중 11 명(32.3\%)이었으며, 1 개 인 경우가 9 명, 2 개인 경우가 2 명, 3 개 이상의 다발성인 경우 는 없었다. 본 연구에서의 소아 및 성인군 간에 유의한 차이 는 보이지 않았으나 평균 발생률인 8 10\%보다 높았다.

셋째, Lund-Mackay 점수에 대한 분석이다. Chung 등은 $\mathrm{ACP}$ 가 상악동염을 악화시키는 인자로 작용하였을 것으로 추정하였다. 21 명 $\mathrm{ACP}$ 환자에서 모두 $\mathrm{ACP}$ 측에 최소 1 개 이 상의 부비동에 부비동염의 소견을 보였고, 반대측의 경우 21 명 중 12 명에서 부비동염의 소견을 보였다. 이환된 부비동의 빈도 순은 상악동, 사골동, 전두동, 접형동 순이었다. 본 연구 에서 성인군보다 소아군에서 $\mathrm{ACP}$ 와 함께 부비동염이 유의 하게 동반된 결과를 보였다.

$\mathrm{ACP}$ 치료 방법은 내시경 부비동수술이 널리 사용되는데 수술 후 합병증이 적고 안전하며 쉽게 사용할 수 있기 때문 이다. 내시경 부비동수술로 $\mathrm{ACP}$ 를 치료한 연구 중 Franche 등 9 은 재발률을 $6.9 \%$ 로 보고하였고, Virós 등 ${ }^{10)}$ 은 재발률을 $4.3 \%$ 로 보고하였다. Lee 등 5 은 소아군 27명 전부에서 MMA 접근법으로, 성인군 29명 중 25명(86.2\%)에서 MMA 접근법 을 사용하였다. 성인군에서 $\mathrm{MMA}+\mathrm{CP}$ 접근법은 29 명 중 4 명 (13.8\%)이었다. 수술 후 성공률은 소아군에서 $88.9 \%$, 성인군 에서는 $93.1 \%$ 였는데, $\mathrm{MMA}$ 접근법으로 $90.4 \%, \mathrm{MMA}+\mathrm{CP}$ 접 근법은 $100 \%$ 였다. 국내 보고에 따르면, Kwon 등 ${ }^{11)}$ 은 MMA 접근법을 시행한 18 예 중 3예(16.6\%)에서 재발하였고, MMA+ $\mathrm{CP}$ 접근법을 병행한 22예에서는 재발이 없었다고 보고하였 다. 본 연구의 성인군에서 $\mathrm{MMA}$ 접근법에 비해 $\mathrm{MMA}+\mathrm{CP}$ 접
근법이 재발률이 높다고 한 이유로는 $\mathrm{MMA}+\mathrm{CP}$ 접근법으로 도 상악동 내 점막의 전반적인 폴립화로 인해 $\mathrm{ACP}$ 의 기시부 를 확인하기 어려웠던 경우로 완전 제거를 확신하기 어려웠 다. $\mathrm{ACP}$ 치료에 대한 연구들을 종합해 보면, $\mathrm{MMA}$ 와 병행 하여 $\mathrm{CP}$ 접근법을 이용하면 넓은 시야와 용이한 기구의 접 근성으로 $\mathrm{MMA}$ 단독 접근법보다 재발을 줄일 수 있을 것으 로 생각된다.

본 연구결과를 요약하면, 소아군와 성인군에 따른 $\mathrm{ACP}$ 방 사선학적 병기에는 차이가 보이지 않았고, 반대측 저류낭종 은 일반적인 발생률보다 높았다. L-M 점수결과, 성인군보다 소아군에서 부비동염이 유의하게 동반된 결과를 보여 $\mathrm{ACP}$ 치료와 동시에 동반된 부비동염 치료에도 관심을 가져야 할 것으로 생각된다.

\section{REFERENCES}

1) Berg $\mathrm{O}$, Carenfelt $\mathrm{C}$, Sobin A. On the diagnosis and pathogenesis of intramural maxillary cysts. Acta Otolaryngol 1989;108(5-6):464-8.

2) Frosini P, Picarella G, De Campora E. Antrochoanal polyp: analysis of 200 cases. Acta Otorhinolaryngol Ital 2009;29(1):21-6.

3) Chung SK, Chang BC, Dhong HJ. Surgical, radiologic, and histologic findings of the antrochoanal polyp. Am J Rhinol 2002;16(2):71-6.

4) Lund VJ, Mackay IS. Staging in rhinosinusitus. Rhinology 1993;31 (4):183-4.

5) Lee DH, Yoon TM, Lee JK, Lim SC. Difference of antrochoanal polyp between children and adults. Int J Pediatr Otorhinolaryngol 2016;84:143-6.

6) Berg O, Carenfelt C, Silfverswärd C, Sobin A. Origin of the choanal polyp. Arch Otolaryngol Head Neck Surg 1988;114(11):1270-1.

7) Balikci HH, Ozkul MH, Uvacin O, Yasar H, Karakas M, Gurdal M. Antrochoanal polyposis: analysis of 34 cases. Eur Arch Otorhinolaryngol 2013;270(5):1651-4

8) Chung SK, Lee CK, Lee HS. Sinus CT Findings of antrochoanal polyp. Korean J Otolaryngol-Head Neck Surg 2003;46(1):54-8.

9) Franche GL, Granzotto EH, de Borba AT, Hermes F, Saleh Cde S, de Souza PA. Endoscopic polipectomy with middle meatal antrostomy for antrochoanal polyp treatment. Braz J Otorhinolaryngol 2007; 73(5):689-92.

10) Virós Porcuna D, Montserrat Gili JR, Gras Cabrerizo JR, López Vilas M, Pujol Olmo A. [Unilateral benign choanal polyp: review of 51 patients]. Acta Otorrinolaringol Esp 2008;59(2):52-6.

11) Kwon SH, Kim KM, Kim W. The role of endoscopic sinus surgery with transcanine approach in antrochoanal polyps. Korean J Otolaryngol-Head Neck Surg 2000;43(9):956-60. 